\title{
Wirausaha Santri Berbasis Budidaya Tanaman Hidroponik
}

\author{
Ahmad Izzuddin \\ Universitas Islam Negeri Walisongo Semarang
}

\begin{abstract}
Cultivation of hydroponic plants need to be socialized in detail and depth to the students Ponpes Life Skill DaarunNajaah. In addition to training students to grow plants that are effective and efficient, training hydroponic plant cultivation is expected to train the spirit of independence and entrepreneurial spirit in view of this hydroponic plant is a plant that has the potential to sell on the market because the quality is good for health. Farming with hydroponics system saves $90 \%$ of water use compared with planting in the ground. Hydroponics system has many advantages than conventional systems with their land.
\end{abstract}

\begin{abstract}
Abstrak: Budidaya tanaman hidroponik perlu disosialisasikan secara detail dan mendalam kepada santri Ponpes Life Skill Daarun Najaah. Selain melatih santri untuk bercocok tanaman yang efektif dan efisien, pelatihan budidaya tanaman hidroponik ini diharapkan mampu melatih jiwa kemandirian dan jiwa kewirausahaan mengingat tanaman hidroponik ini merupakan tanaman yang berpotensi untuk di jual di pasaran karena kualitasnya yang baik untuk kesehatan. Bertanam dengan sistem hidroponik menghemat $90 \%$ penggunaan air dibandingkan dengan menanam di tanah. Sistem hidroponik memiliki banyak kelebihan daripada sistem konvensional dalam bertanam.
\end{abstract}

Kata Kunci: wirausaha, santri, hidroponik 


\section{PENDAHULUAN}

Pondok Pesantren Life Skill Daarun Najaah berdiri pada tanggal 12 Mei 2012 terletak di Bukit Beringin Lestari Barat Blok C 131 Wonosari Ngaliyan Semarang. Kebanyakan santri yang mondok disini merupakan Mahasiswa Jurusan Ilmu Falak Fakultas Syari'ah dan Hukum UIN Walisongo Semarang sehingga merupakan Markaz Falakiyyah Indonesia yang mencetak kader-kader falak. Meski demikian banyak juga Mahasiswa dari berbagai Jurusan yang nyantri di Ponpes Life Skill Daarun Najaah.

Sebagai pengasuh, Bapak Dr. KH. Ahmad Izzuddin, M. Ag. dan Ibu Aisyah Handayani, S. Ag. dengan penuh semangat tidak pernah bosan mendorong kepada semua santrinya untuk meraih kesuksesan, keshalihan dan keselamatan. Para santri tidak hanya dibekali ilmu-ilmu secara teoritis namun mereka di tuntut untuk bisa mempraktekkan dan mengaplikasikannya secara nyata. Beberapa Lembaga dibentuk guna mencetak kader-kader sesuai bakat dan minatnya diantaranya yaitu Lembaga Hisab Rukyat al-Husna, Lembaga Bimbingan Belajar Anak Sholeh, Bulletin An-Najwa, Repacking Snack Al-nafa dan lain sebagainya.

Letak Ponpes yang berada diperbukitan menjadikan sebagai tempat strategis untuk bercocok tanaman di lingkungan pondok, namun mengingat ladang yang terbatas menjadikan kurang efektif dan efisien sehingga diperlukan cara lain. Baru-baru ini sedang populer di masyarakat yaitu cara bercocok tanam tanpa menggunakan media tanah yaitu hidroponik.

Berdasarkan uraian diatas maka budidaya tanaman hidroponik perlu disosialisasikan secara detail dan mendalam kepada santri Ponpes Life Skill Daarun Najaah. Selain melatih santri untuk bercocok tanaman yang efektif dan efisien, pelatihan budidaya tanaman hidroponik ini diharapkan mampu melatih jiwa kemandirian dan jiwa kewirausahaan mengingat tanaman hidroponik ini merupakan tanaman yang berpotensi untuk di jual di pasaran karena kualitasnya yang baik untuk kesehatan. Terlebih santri Pondok Pesantren Life Skill Daarun Najaah berasal dari berbagai daerah di Indonesia, sehingga nantinya santri yang sudah lulus diharapkan mampu menyebarluaskan cara berbudidaya tanaman hidroponik ini di daerah masing-masing.

Pondok Pesantren Life Skill Daarun Najaah merupakan pesantren yang selalu menanamkan jiwa wirausaha kepada para santri. Wirausaha merupakan ladang kerja yang dapat memberikan lapangan kerja kepada orang lain sehingga dapat meningkatkan perekonomian masyarakat sesuai dengan harapan bersama. Dengan bekal ilmu wirausaha yang di dapatkan di Pondok, alumni dari Pondok 
Pesantren Life Skill Daarun Najaah diharapkan mampu menjadi pioneer dalam kehidupan wirausaha di tengah-tengah masyarakat.

Sampai saat ini, wirausaha yang berkembang di Pondok Pesantren Life Skill Daarun Najaah diantaranya ialah bimbingan belajar, re-packing snack, penjualan buku-buku Islami, kerupuk santri, penjualan pulsa, dan hidroponik. Saat ini, hidroponik sedang menjadi wirausaha yang populer di kalangan masyarakat. Hal ini dikarenakan hidroponik merupakan ladang usaha yang mempunyai prospek masa depan yang cerah mengingat semakin terbatasnya ladang pertanian di Indonesia.

Hidroponik adalah suatu metode bercocok tanam tanpa menggunakan media tanah, melainkan dengan menggunakan larutan mineral bernutrisi atau bahan lainnya yang mengandung unsur hara seperti sabut kelapa, serat mineral, pasir, pecahan batu bata, serbuk kayu, dan lain-lain sebagai pengganti media tanah.

Tanaman hidroponik bisa dilakukan secara kecil-kecilan di rumah sebagai suatu hobi ataupun secara besar-besaran dengan tujuan komersial. Budidaya tanaman hidroponik ini sangatlah cocok untuk daerah yang mempunyai lahan sempit. Dikarenakan budidaya tanaman ini tidak memerlukan lahan yang luas, bisa juga dilakukan di pekarangan atau di teras rumah.

Beberapa kelebihan tanaman dengan sistem hidroponik ini antara lain : 1) Ramah lingkungan karena tidak menggunakan pestisida atau obat hama yang dapat merusak tanah, menggunakan air hanya 1/20 dari tanaman biasa, dan mengurangi $\mathrm{CO} 2$ karena tidak perlu menggunakan kendaraan atau mesin. 2) Tanaman ini tidak merusak tanah karena tidak menggunakan media tanah dan juga tidak membutuhkan tempat yang luas. 3) Bisa memeriksa akar tanaman secara periodik untuk memastikan pertumbuhannya. 4) Pemakaian air lebih efisien karena penyiraman air tidak perlu dilakukan setiap hari sebab media larutan mineral yang dipergunakan selalu tertampung di dalam wadah yang dipakai. 5) Hasil tanaman bisa dimakan secara keseluruhan termasuk akar karena terbebas dari kotoran dan hama. 6) Lebih hemat karena tidak perlu menyiramkan air setiap hari, tidak membutuhkan lahan yang banyak, media tanaman bisa dibuat secara bertingkat. 7) Pertumbuhan tanaman lebih cepat dan kualitas hasil tanaman dapat terjaga. 8) Bisa menghemat pemakaian pupuk tanaman. 9) Tidak perlu banyak tenaga kerja. 10) Lingkungan kerja lebih bersih. 11) Tidak ada masalah hama dan penyakit tanaman yang disebabkan oleh bakteri, kulat dan cacing nematod yang banyak terdapat dalam tanah. 12) Dapat tanam di mana saja bahkan di garasi dan tanah yang berbatu. Dan 13) Dapat ditanam kapan saja karena tidak mengenal musim. 
Beberapa tanaman yang sering ditanam secara hidroponik, adalah sayursayuran seperti bak choy, brokoli, sawi, kailan, bayam, kangkung, tomat, bawang, bahkan strowbery, dll. Tanaman demikian sering menjadi pilihan utama kaum vegan/vegetarian yang sangat memperhatikan proses suatu tanaman apakah terdapat pembunuhan makhluk hidup, tercampur unsur kimiawi, konservasi lingkungan dan usaha penghijauan.

Kegiatan pemberdayaan masyarakat yang diberikan kepada santri pondok pesantren life skill Daarun Najaah ini bertujuan untuk memberikan pembekalan pada santri sebagai upaya meningkatkan keterampilan santri dalam budidaya tanaman hidroponik yang nantinya akan menjadi penunjangekonomi kreatif di masyarakat. Setelah pelatihan ini diharapkan semua santri life skill daarunnajaah bisa menerapkannya di daerahnya masing-masing.

Pemberdayaan masyarakat melalui berbudidaya tanaman hidroponik di pondok pesantren life skill Daarun Najaah diharapkan dari pendampingan ini bertujuan untuk, a) Meningkatkan keterampilan mahasiswa santri dalam hal bercocok tanam hidroponik, b) Mendapatkan ladang usaha baru, dalam menanggulangi pengangguran, c) Memunculkan kreativitas mahasiswa santri, untuk menunjang ekonomi kreatif di masyarakat, d) Mendaur ulang sampah anorganik sebagai media tanam hidroponik, e) Efisiensi tanah dan air, karena tidak perlu menyiramkan air setiap hari, tidak membutuhkan lahan yang banyak, media tanaman bisa dibuat secara bertingkat, dan f) Peserta pelatihan dapat mengajarkan kemampuan bercocok tanam hidroponiknya terhadap masyarakat di daerahnya masing-masing.

\section{STRATEGI DAN METODE}

Kegiatan ini didesain dalam bentuk pelatihan bercocok tanam hidroponikyang dilakukan secara intensif dan bertahap. Sedangkan tahapan dan metode yang digunakan dalam pelatihan tersebut di antaranya adalah; pertama, Tahap Awal. Tahap ini meliputi 1) Pemantapan tim pelaksana (panitia penyelenggara). 2) Konsultasi dengan tutor tanaman hidroponik yang ahli. 3) Sosialisasi kepada santri Pondok Pesantren Life Skill Daarun Najaah sebagai peserta pelatihan. 4) Pelatihan efektif.

Kedua, Tahap Pelaksanaan. Tahap ini meliputi a) Pemaparan teknik penanaman hidroponik, terdapat dua teknik utama dalam cara bercocok tanam hidroponik yaitu: 1) Menggunakan larutan; metode ini menggunakan larutan dan tidak membutuhkan media keras untuk pertumbuhan akar, hanya cukup dengan larutan mineral bernutrisi. Contoh cara dalam teknik larutan yang umum dipakai adalah teknik larutan statis dan teknik larutan alir. Dan 2) Menggunakan 
media;metode ini tergantung dari jenis media yang dipergunakan, bisa berupa sabut kelapa, serat mineral, pasir, pecahan batu bata, serbuk kayu, dan lain-lain sebagai pengganti media tanah.

Terlepas dari teknik yang diterapkan, kebanyakan tempat talangan hidroponik terbuat dari plastik, tapi bahan lain juga bisa dipakai termasuk bak beton, kaca, baja, kayu dan bahan solid lainnya. Tempat penampungan harus dijauhkan dari cahaya guna mencegah pertumbuhan lumut di dalam air bernutrisi yang telah diisi.

Tahap selanjutnya, b) Pembuatan perangkat yang diperlukan, sebagaimana melubangi paralon sebagai wadah tanaman hidroponik. Jika menggunakan bahan dari botol bekas, maka harus dipotong menjadi dua bagian. c) Pemotongan rockwool menjadi kecil-kecil, direndam dan dilobangi di bagian tengahnya menggunakan tusuk gigi atau yang lain, untuk menaruh bibit benih sayuran yang akan ditanam. Menunggu selama kurang lebih 4 sampai 7 hari atau setelah benih sayuran tumbuh empat tangkai daun, tanaman siap dipindahkan ke tempat netpot yang selanjutnya ditempatkan ke paralon atau botol yang sudah di lubangi. Dan d) Tiap minggunya dilakukan pengecekan kadar PH yang terkandung dalam air, PH yang normal berkisar 5,5 sampai 7,5. Pengecekan ini dilakukan secara terus menerus sampai buah atau sayuran siap panen untuk mendapatkan hasil yang maksimal.

Tahap terakhir, ketiga, Tahap Evaluasi. Setelah semua rangkaian tahap dijalani, maka langkah terakhir adalah melakukan evaluasi. Evaluasi ini perlu dilakukan supaya kegiatan ke depannya akan lebih baik. Kegiatan ini juga di desain supaya kedepannya dapat dilaksanakan secara berlanjut dengan dana swadaya masyarakat.

\section{BUDIDAYA HIDROPONIK}

Dalam kajian bahasa, hidroponik berasal dari kata bydro yang berarti air dan ponos yang berarti kerja. Jadi, hidroponik memiliki pengertian secara bebas teknik bercocok tanam dengan menekankan pada pemenuhan kebutuhan nutrisi bagi tanaman, atau dalam pengertian sehari-hari bercocok tanam tanpa tanah. Dari pengertian ini terlihat bahwa munculnya teknik bertanam secara hidroponik diawali oleh semakin tingginya perhatian manusia akan pentingnya kebutuhan pupuk bagi tanaman.

Di mana pun tumbuhnya sebuah tanaman akan tetap dapat tumbuh dengan baik apabila nutrisi (unsur hara) yang dibutuhkan selalu tercukupi. Dalam konteks ini fungsi dari tanah adalah untuk 
penyangga tanaman dan air yang ada merupakan pelarut nutrisi, untuk kemudian bisa diserap tanaman. Pola pikir inilah yang akhirnya melahirkan teknik bertanam dengan hidroponik, di mana yang ditekankan adalah pemenuhan kebutuhan nutrisi.

Pada mulanya, kegiatan membudidayakan tanaman yang daratan tanpa tanah ditulis pada buku Sylva Sylvarum oleh Francis Bacon dibuat pada tahun 1627, dicetak setahun setelah kematiannya. Teknik budidaya pada air menjadi penelitian yang populer setelah itu. Pada tahun 1699, John Woodward menerbitkan percobaan budidaya air dengan spearmint. Ia menemukan bahwa tanaman dalam sumber-sumber air yang kurang murni tumbuh lebih baik dari tanaman dengan air murni.

Pada tahun 1842 telah disusun daftar sembilan elemen diyakini penting untuk pertumbuhan tanaman, dan penemuan dari ahli botani Jerman Julius von Sachs dan Wilhelm Knop, pada tahun-tahun 1859-1865, memicu pengembangan teknik budidaya tanpa tanah. Pertumbuhan tanaman darat tanpa tanah dengan larutan yang menekankan pada pemenuhan kebutuhan nutrisi mineral bagi tanaman. Dengan cepat menjadi standar penelitian dan teknik pembelajaran, dan masih banyak digunakan saat ini. Sekarang, Solution culture dianggap sebagai jenis hidroponik tanpa media tanam inert, yang merupakan media tanam yang tidak menyediakan unsur hara.

Pada tahun 1929, William Frederick Gericke dari Universitas California di Berkeley mulai mempromosikan secara terbuka tentang Solution culture yang digunakan untuk menghasilkan tanaman pertanian. Pada mulanya dia menyebutnya dengan istilah aquaculture (atau di Indonesia disebut budidaya perairan), namun kemudian mengetahui aquaculture telah diterapkan pada budidaya hewan air. Gericke menciptakan sensasi dengan menumbuhkan tomat yang menjalar setinggi duapuluh lima kaki, di halaman belakang rumahnya dengan larutan nutrien mineral selain tanah. Berdasarkan analogi dengan sebutan Yunani kuno pada budi daya perairan, ilmu budidaya bumi, Gericke menciptakan istilah bidroponik pada tahun 1937 (meskipun ia menegaskan bahwa istilah ini disarankan oleh WA Setchell, dari University of California) untuk budidaya tanaman pada air.

Pada laporan Gericke, dia mengklaim bahwa hidroponik akan merevolusi pertanian tanaman dan memicu sejumlah besar permintaan informasi lebih lanjut. Pengajuan Gericke ditolak oleh pihak universitas tentang penggunaan greenhouse dikampusnya untuk eksperimen karena skeptisme orang-orang administrasi kampus. dan ketika pihak Universitas berusaha memaksa dia untuk membeberkan resep nutrisi pertama yang dikembangkan di rumah, ia meminta 
tempat untuk rumah kaca dan saatnya untuk memperbaikinya menggunakan fasilitas penelitian yang sesuai. Sementara akhirnya ia diberikan tempat untuk greenhouse, Pihak Universitas menugaskan Hoagland dan Arnon untuk menyusun ulang formula Gericke, pada tahun 1940, setelah meninggalkan jabatan akademik di iklim yang tidak menguntungkan secara politik, dia menerbitkan buku berjudul Complete Guide to Soil less Gardening.

Teknik hidroponik banyak dilakukan dalam skala kecil sebagai hobi di kalangan masyarakat Indonesia. Pemilihan jenis tanaman yang akan dibudidayakan untuk skala usaha komersial harus diperhatikan, karena tidak semua hasil pertanian bernilai ekonomis. Jenis tanaman yang mempunyai nilai ekonomi tinggi untuk dibudidayakan di hidroponik yaitu: ${ }^{1}$ Paprika, Tomat, Timun Jepang, Melon, Terong Jepang, Selada, Sawi, Cabe, dan Packcooy.

Pada awalnya Gericke mendefinisikan pertumbuhan tanaman hidroponik dengan larutan nutrien mineral. Hidroponik merupakan bagian dari budidaya tanpa tanah. Banyak budidaya tanpa tanah namun dengan larutan untuk hidroponik.

Tanaman yang tidak ditumbuhkan dengan cara pada umumnya, akan dapat untuk tumbuh menggunakan sistem lingkungan yang dapat dikendalikanseperti hidroponik. Tampaknya NASA jugamemanfaatkan hidroponik pada program luar angkasanya. Ray Wheeler, seorang ahli fisiologi tanaman di Laboratorium Space Center Space Life Science, Kennedy, percaya bahwa hidroponik akan berkontribusi membuat kemajuan dalam perjalanan luar angkasa. Dia menyebutnya sebagai sistem bioregenerative life support. ${ }^{2}$

Dalam berhidroponik, terdapat 6 (enam) system hidroponik: ${ }^{3}$ pertama, Wick System. Sistem Wick adalah sistem yang paling sederhana. Disebut juga sistem pasif dengan kondisi air menggenang, yang berarti tidak ada bagian yang bergerak. Larutan nutrisi ditarik ke dalam media tumbuh dari wadah nutrisi dengan sumbu, biasanya sumbu yang digunakan berupa kain flannel atau jenis bahan lain yang mudah menyerap air. Berbagai media dapat digunakan dalam Sistem wick, sekam bakar, rockwool, perlite/vermikulit, atau dapat pula menggunakan hidroton juga zeolit.

${ }^{1}$ J. Benton Jones, dkk., Complete Guide forGrowing PlantsHydroponically, South Carolina, USA: CRCPressTaylor\& Francis Group, 2014, hlm.

2 Sylvia Bernstein., Aquaponic gardening (a step-by-step guide to raising vegetables and fish Together), Canada: New Society Publishers, 2011, hlm. 3.

3 https://id.wikipedia.org/wiki/Hidroponik 
Kelemahan terbesar dari sistem ini adalah jika tanaman besar dan menggunakan air lebih banyak dari daya serap sumbu. Sedangkan dalam prosesnya meliputi, semai, pindah tanam ke sistem wick, perawatan dan panen.

\section{Sistem Sumbu (Wick System)}

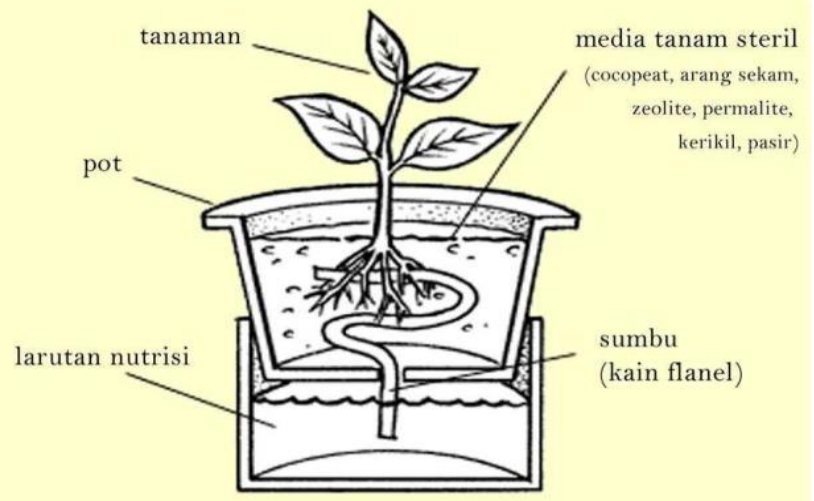

Gambar 2.1 Wick System

Kedua, NFT (Nutrient Film Technique) System. Prinsip dari system ini adalah tanaman tumbuh pada lapisan nutrisi yang dangkal dan tersirkulasi sehingga tanaman dapat memperoleh cukup air, nutrisi dan oksigen.

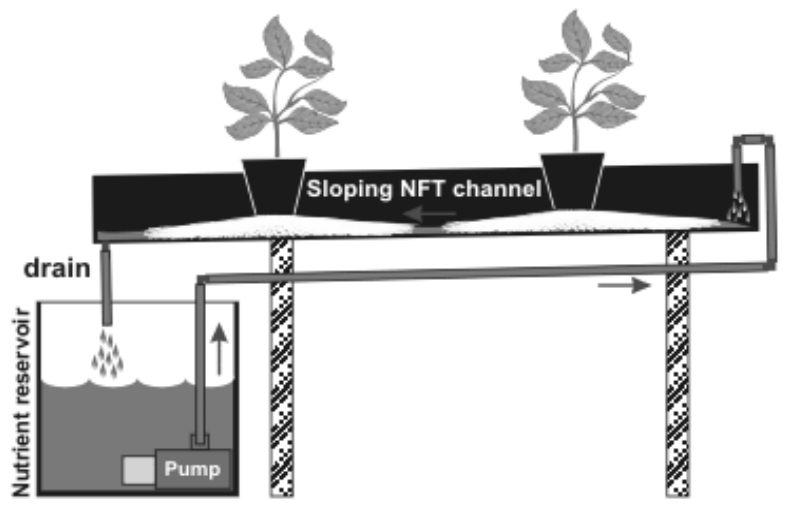

Fig 1.1 NFT system (Basic layout)

Gambar 2.2 NFT System 
Ketiga, Floating Raft System (Rakit Apung). Dalam system ini Tanaman ditancapkan pada lubang styrofoam yang mengapung diatas permukaaan larutan nutrisi dalam suatu bak penampung atau kolam sehingga akar tanaman terapung atau terendam dalam larutan nutrisi.

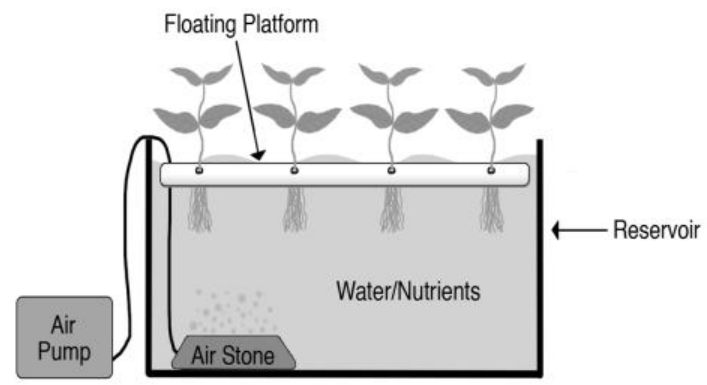

Gambar 2.3 Floating Raft System

Keempat, Drip System. Pada system ini Nutrisi diberikan dengan cara meneteskan air dan nutrisi secara terus menerus selama pertumbuhan tanaman. Pemberian nutrisi diarahkan langsung ke daerah perakaran tanaman sehingga nutrisi dapat segera terserap oleh tanaman.

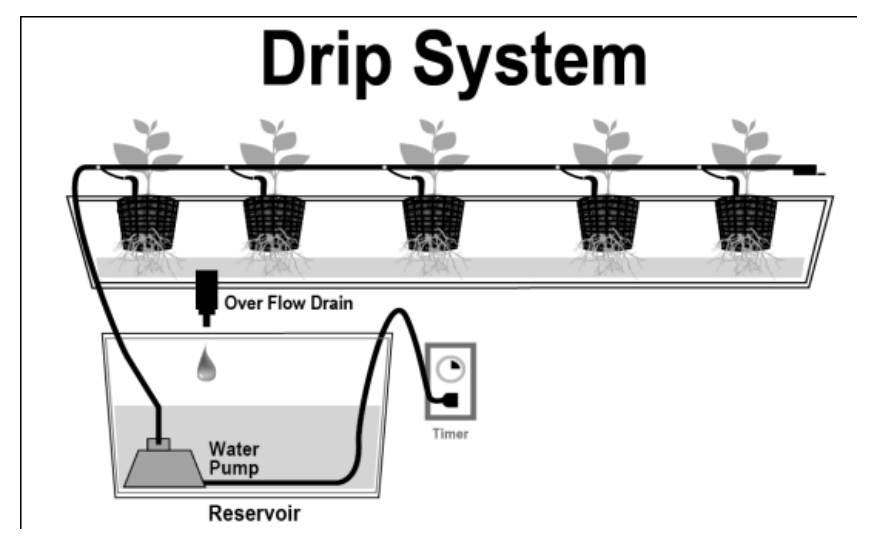

Gambar 2.4 Drip System

Kelima, EBB dan Flow System (Flood and Drain). Sistem EBB dan Flow ( sistem pasang surut) ini merupakan salah satu sistem hidroponik yang unik karena prinsip kerjanya yaitu tanaman mendapatkan air, oksigen dan nutrisi 
melalui pompaan dari bak penampung yang dipompa melewati media kemudian membasahi akar tanaman (pasang), kemudian selang beberapa waktu air bersama nutrisi akan turun (surut) kembali melewati media menuju bak penampungan.

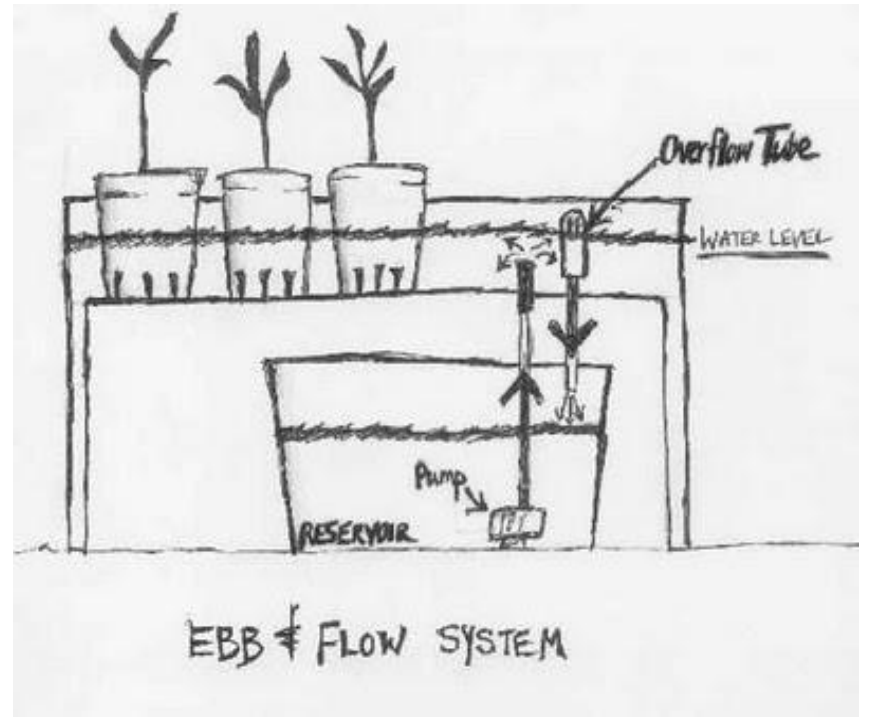

Gambar 2.5 EBB dan Flow System

Keenam, Aeroponics System. Sistem Aeroponics ini Air dan nutrisi yang akan diserap tanaman diberikan dalam bentuk butiran kecil atau kabut. Pengkabutan ini berasal dari pompa dari bak penampungan yang disemprotkan menggunakan nozzel sehingga nutrisi yang diberikan akan lebih cepat terserap akar tanaman.

Penyemprotan dilakukan berdasarkan durasi waktu yang diatur menggunakan timer. Penyemprotan dilakukan ke bagian akar tanaman yang sengaja digantung. Air dan nutrisi yang telah disemprot akan masuk menuju bak penampungan untuk disemprotkan kembali.

Beberapa kelebihan tanaman dengan sistim hidroponik ini antara lain: ${ }^{4}$ 1) Ramah lingkungan karena tidak menggunakan pestisida atau obat hama yang dapat merusak tanah, menggunakan air hanya 1/20 dari tanaman biasa, dan mengurangi CO2 karena tidak perlu menggunakan kendaraan atau mesin. 2) Tanaman ini tidak merusak tanah karena tidak menggunakan media tanah dan juga tidak membutuhkan tempat yang

${ }^{4}$ https://sumansutra.wordpress.com/tanamanhidroponi/ 
luas. 3) Bisa memeriksa akar tanaman secara periodik untuk memastikan pertumbuhannya. 4) Pemakaian air lebih efisien karena penyiraman air tidak perlu dilakukan setiap hari sebab media larutan mineral yang dipergunakan selalu tertampung di dalam wadah yang dipakai. Dan 5) Hasil tanaman bisa dimakan secara keseluruhan termasuk akar karena terbebas dari kotoran dan hama.

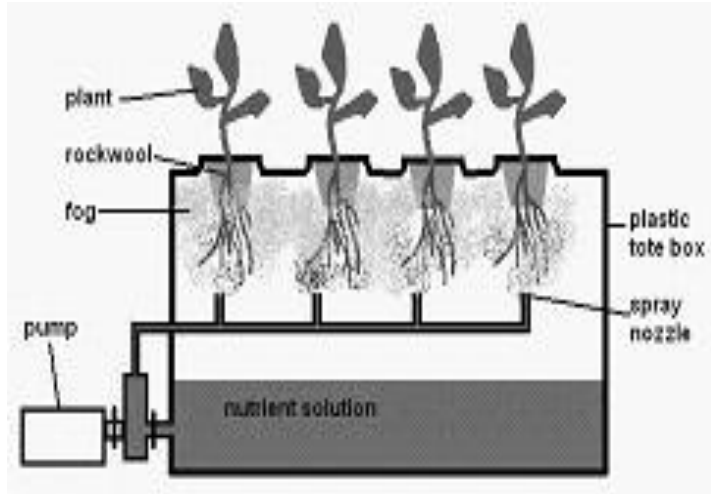

Gambar 2.6 Aeroponics System

\section{HASIL DAN PEMBAHASAN}

Kegiatan pengabdian masyarakat di Pondok Pesantren Life Skill Daarun NajaahSemarang didesaindalam bentukpelatihan berbudidaya tanaman hidroponik secara intensif danbertahap.Pelatihan ini dilaksanakan setiap akhir pekan mengingat pada hari tersebut merupakan hari libur santri. Berikut adalah tahapan pelaksanaan dalam pelatihanberbudidaya tanaman hidroponikdi Pondok Pesantren Life Skill Daarun Najaah Semarang yaitu:

Pertama, Tahap Persiapan. Tahap ini diawali pemantapan tim pelaksana, dilanjutkan dengan konsultasi dengan tutor ahli hidroponik. Selain melakukan koordinasi, tim pelaksana pengabdian juga melakukan konsultasi dengan tutor ahli dalam bidang penanaman hidroponik. Konsultasi dilakukan untuk membahas teknis pelatihan yang efektif dan efisien agar kegiatan pelatihan dapat tepat sasaran. Tutor ahli pelatihan hidroponik di Pondok Pesantren Life Skill Daarun Najaah yaitu Bapak Tunggul Indriyono dan Ibu HarjantiSetyorini.

Selanjutanya dilakukan Sosialisasi kepada santri Pondok Pesantren Life Skill Daarun Najaah. Sosialisasi ini dilakukan selama bulan Juni 2016. Sosialisasi 
ini dilakukan guna menyamakan perspepsi santri terkait pentingnya bercocok tanam khususnya dengan metode hidroponik, karena setelah pelatihan ini para santri diharapkan mampu menerapkan dan menyebarluaskan cara bertanam hidroponik kepada masyarakat daerahnya masing-masing. Selain itu bertanam hidroponik juga dapat dijadikan sebagai wahana wirausaha yang profit, sehingga para santri nantinya tidak akan menjadi pengangguran setelah lulus.

Kedua, Tahap Pelaksanaan. Dimulai dengan membuat instalasi. Sebelum bertanam hidroponik, langkah pertama yang dilakukan adalah membuat instalasi untuk tempat tanaman hidroponik tumbuh. Instalasi untuk bercocok tanam hidroponik menyesuaikan dengan sistem yang digunakan, sistem bertanam hidroponik secara umum ada 6 macam yaitu NFT System, Wick System, Aeroponic System, EBB and Flow System, Drip System dan Floating Raft System.

Sistem yang kami gunakan dalam pelatihan Hidroponik di Pondok Pesantren Life Skill Daarun Najaah yaitu menggunakan NFT System. NFT (Nutrient Film Technique) System yaitu salah satu sistem hidroponik, dimana akar tanaman terendam dalam larutan nutrisi yang dialirkan dengan ketebalan sekitar 3-5 mm. Jalur air pada sistem NFT dapat dibuat menggunakan talang air yang dimodifikasi, plastik yang kedua sisinya dijepit membentuk segi tiga, ataupun gully khusus yang beredar di pasaran.

Berikut ini adalah alat-alat dan bahan yang dibutuhkan untuk membuat instalasi tanam hidroponik dengan menggunakan NFT System, yaitu: Mesin Boor, Gergaji, Mesin Gerinda, Pompa Air 40-60 watt, Selang air 3/4", Tourne/Tandon Air 200-500 lt, Tds/Tdsec meter, pH meter, Talang U (sinar daku), Tutup talang, Lem pralon, Pralon 1", Knee 1" , Pralon 1/2", Dop pralon 1/2", Tee 1/2", Stop Kran 1/2", Besi hitam tbl $1.5-1.8 \mathrm{~mm}$, dan Plastik UV $6 \times 2 \mathrm{~m}$.

Tahap berikutnya Pemupukan. Setelah meja instalasi selesai dibuat, langkah selanjutnya yaitu menyiapkan pupuk yang dibutuhkan oleh tanaman hidroponik.Pupuk tersebut di campurkan dengan air dalam tendon karena air merupakan unsur utama yang harus ada pada sistem hidroponik. Pemupukan hidroponik terdiri dari beberapa unsur yaitu: 1) Nutrisi Hidroponik. Berupa Unsur Hara Makro: Carbon (C),Hidrogen(H), Oksigen(O),Nitrogen (N), Phosphor (P), Kalium(K), Calcium (C), Magnesium (Mg), Sulfur (S). Dan Unsur Hara Mikro: Ferrum(Fe), Manganium(Mn), Cuprum (Cu), Zincum (Zn), Boron (B), Molybdenum (Mo). Unsur hara $\mathrm{C}, \mathrm{H}$, dan $\mathrm{O}$ tersedia dari udara sedangkan unsur hara makro dan mikro lainnya didapat dari pemupukan. 2) Pekatan $A+B$ Mix. Bahan-bahan AB-MIX terdiri atas; Pekatan A terdiri dari : Calcium Nitrat 
(Ca(NO3)2), Potassium Nitrat (KNO3), Fe-EDTA. Pekatan B terdiri dari : Magnesium Sulfat (MgSO4), Mono Kalium Phosphat (KH2PO4), Potassium Sulfat (K2SO4), Amonium Sulfat ((NH4)2SO4), unsur-unsur Micro. Mono Kalium Phosphat /MKP berperan sebagai buffer, supaya $\mathrm{pH}$ tidak terlalu banyak berubah ( $\mathrm{pH}$ swing). Penambahan Amonium Sulfat / (NH4)2SO4 membuat $\mathrm{pH}$ cenderung asam, dan tanaman meraksasa. Unsur-unsur micro diperlukan dalam jumlah sedikit. Pupuk untuk pertanian konvensional (misal: NPK Mutiara) sering tidak menyertakan unsur micro di dalamnya. Tidak semua bahan dijual bebas. Potassium Nitrat, Amonium Sulfat(ZA), dan unsur-unsur mikro agak susah didapat di pasaran.

Selanjutnya 2) $\mathrm{pH}$. $\mathrm{pH}$ nutrisi hidroponik yang baik berada pada range 5.5-6.5. Pada range tersebut ketersediaan unsur hara berada pada kondisi optimal. Jika $\mathrm{pH}$ terlalu asam atau terlalu basa, ada unsur yang mulai mengendap/teroksidasi/tidak dapat diserap oleh tanaman. Tanaman akan menunjukkan gejala defisiensi. Misalnya daun menjadi kuning. Jika tampak endapan seperti kapur pada tandon, biasanya $\mathrm{pH}$ terlalu basa. Tambahkan HNO3 (asam nitrat) / H3PO4 (asam phosphat) / H2SO4 (asam sulfat). Jika pH terlalu asam tambahkan $\mathrm{KOH}$ (potassium hidrokida). Semua bahan untuk menaikkan atau menurunkan $\mathrm{pH}$ sangat berbahaya, sehingga harus diencerkan minimal 30\% supaya lebih aman. Gunakan dengan hati-hati. Pada $\mathrm{pH}$ berlaku skala logaritma. Artinya pH $6=10$ kali lebih masam dibandingkan $\mathrm{pH} 7$. Fluktuasi $\mathrm{pH}$ yang terlalu besar dan sering terjadi dapat membuat tanaman stress.

Berikutnya EC. Meliputi; Satuan EC adalah $\mathrm{mS} / \mathrm{cm}$. TDS yang umum beredar (Hanna, HM-Digital, non merek dari china) biasanya memiliki konversi EC $1=500$ ppm. Jika EC terlalu kecil, maka tanaman lambat tumbuh; penampilan, bobot, rasa serta aroma kurang. Jika EC terlalu besar, maka tanaman keracunan, tepi daun terlihat kering/menghitam (tip burn), daun rontok.

Ketiga, Penanaman Tanaman Hidroponik. Setelah pemupukan selesai dilakukan maka tanaman hidroponik siap untuk di tanam. Berikut merupakan tahapan penanaman hidroponik menggunakan system NFT. Meliputi 1) Pembenihan(0-4 hari). Berikut ini merupakan langkah-langkah untuk pembenihan: Siapkan benih dan pastikan kualitas benihnya. Rendam benih dengan air hangat biarkan dingin kurang lebih 30 menit, lalu tiriskan. Sementara itu, sebelum rockwool dipotong bisa dibasahi sebentar dengan menggunakan sprayer agar debu potongan rockwool tidak beterbangan. Potong rockwool membentuk papan / bata menggunakan pisau bergerigi / gergaji besi dengan 
tinggi : 2,5 cm lalu kerat-kerat tanpa terputus dengan ukuran P: 2,5 cm x L: 2,5 $\mathrm{cm}$. Atau, potong rockwool berbentuk kubus dengan ukuran seperti di atas. Lubangirockwool menggunakan tusuk gigi / sumpit sedalam 2-3x besar benih. (Jangan terlalu dalam, agar daunnya mudab keluar). Masukkan benih menggunakan ujung tusuk gigi yang dibasahi. Tata rockwool tersebut di nampan. Semprot dengan sprayer yang lembut menggunakan air biasa secukupnya, pagi dan sore. (Jangan terlalu basab). Simpan di tempat teduh atau bisa juga ditutup menggunakan plastik hitam untuk menjaga kelembabannya. Cek benih setiap pagi. Jika benih sudah sprout / pecah (kira-kira 1-3 hari), segera singkirkan plastik hitamnya(Jangan digunakan lagi untuk menutup benib agar tidak etiolasi). Segera kenalkan pada sinar matahari setiap pagi hari antara jam $06.00-10.00$ WIB. Boleh langsung terpapar sinar matahari, asal selalu dijaga kelembabannya. Setelah muncul4 daun (kira-kira 5 hari), pindahkan tanaman beserta rockwoolnya ke meja (gully) penyemaian.

Selanjutnya yang 2) Penyemaian (5-14 hari). Langkah-langkah untuk penyemaian merliputi: Setelah benih muncul 4 daun (kira-kira berumur 5 hari), maka benih siap untuk dipindah ke meja penyemaian. Usahakan sayuran tersebut di taruh pada tempat yang terkena matahari langsung, jika memungkinkan sayuran tersebut terlindung dari hujan. Lakukan pengecekan tinggi permukaan air larutan di gully kira-kira $1 \mathrm{~cm}$. Setting $\mathrm{pH}$ air senilai 5,5. Dan Setting pekatan air menggunakan TDS senilai 700 ppm.

Pada saat usia tanaman masih Remaja (15-29), langkah-langkah untuk merawat tanaman vegetatif diantaranya; Setelah tanaman berusia 15 hari, maka pindahkan ke meja vegetative/remaja. Usahakan sayuran tersebut di taruh pada tempat yang terkena matahari langsung, jika memungkinkan sayuran tersebut terlindung dari hujan. Lakukan pengecekan tinggi permukaan air larutan di gully kira-kira 1,5 cm. Setting $\mathrm{pH}$ air senilai 5,7. Setting pekatan air menggunakan TDS senilai 800 ppm.

Kemudia pada usia Dewasa (30-40 hari), langkah-langkah untuk merawatnya berupa; Setelah tanaman berusia 30 hari memasuki masa generatif, maka pindahkan ke meja dewasa. Usahakan sayuran tersebut di taruh pada tempat yang terkena matahari langsung, jika memungkinkan sayuran tersebut terlindung dari hujan. Lakukan pengecekan tinggi permukaan air larutan di gully kira-kira $1,8 \mathrm{~cm}$. Setting $\mathrm{pH}$ air senilai 6 . Setting pekatan air menggunakan TDS senilai 900 ppm.

Dan terakhir usia Panen (41-45 hari), langkah-langkah untuk memanen tanaman hidroponik berupa; Lebih kurang 40 hari sayuran yang ditanam sudah dapat dipanen. Cara memanen dilakukan dengan cara mengangkat tanaman dari 
Meja Produksi. Kemudian Cabut tanaman dari pot kecilnya, bersihkan pot dari sisa sisa akar sayur dan pot tersebut dapat digunakan untuk penanaman berikutnya .

\section{TAHAP EVALUASI DAN MONITORING}

Setelah semua rangkaian tahap dijalani, maka langkah terakhir adalah melakukan evaluasi dan monitoring. Evaluasi ini perlu dilakukan supaya kegiatan ke depannya akan lebih baik. Kegiatan ini juga di desain supaya kedepannya dapat dilaksanakan secara berlanjut dengan dana swadaya masyarakat. Selain itu, pengawasan atau monitoring pasca kegiatan pelatihan juga penting untuk dilakukan. Pengawasan ini dilakukan dengan system koordinasi antara tutor ahli dan pelaksana pengabdian.

Pemantauan dilakukan selama 2-3 bulan. Hal-hal yang akan dipantau meliputi kegiatan budidaya tanaman hidroponik para santri ponpes life skill Daarun Najaah, kualitas hasil panen, dan jiwa wirausaha santri di lihat dari pemasaran yang dilakukan setelah panen.

Dalam pelaksanaan pengabdian masyarakat yang berbentuk pelatihan budidaya tanaman hidroponik, di harapkan para santri untuk bisa mempunyai skill, sehingga nantinya setelah wisuda tidak menjadi pengangguran.

Dalam pelaksanaanya ada beberapa kendala yang dihadapi seperti, Mahasiswa santri masih belum sadar akan pentingnya kegiatan pelatihan ini, sehingga sebagian dari mereka ada yang menyepelekannya. Kurangnya kreatifitas santri, sehingga kegiatan terkesan kurang meriah. Keterbatasan alat dan bahan untuk membuat instalasi, sehingga pembuatan instalasi kurang maksimal. Letak ponpes yang tidak rata, sehingga kesulitan untuk membuat etalase yang sempurna. Panas matahari yang terik ketika pagi hari dan terlalu teduh saat sore hari. Serangan hama pada tanaman hidroponik.

Dari gambaran tersebut, solusi guna perbaikan kegiatan yang akan datang, antara lain; Memberi sosialisasi yang mendalam kepada santri terkait manfaat dan pentingnya budidaya tanaman hidroponik. Memberi support kepada santri. Menyiapkan alat dan bahan sebelum pelaksanaan kegiatan. Manajemen waktu pelaksanaan kegiatan yang matang. Memilih tempat yang layak untuk tempat instalasi. Membuat atap pada instalasi Antisipasi terhadap serangan hama pada tanaman hidroponik. 


\section{KESIMPULAN}

Hidroponik merupakan teknologi untuk menumbuhkan tanaman dalam larutan nutrisi yang mengandung semua unsur hara yang dibutuhkan tanaman, dengan atau tanpa menggunakan media yang inert seperti: kerikil, vermiculite, rockwool, peat moss, serbuk gergaji, cocopeat, dan lain-lain sebagai penyangga tanaman. Berhidroponik menghemat 90\% penggunaan air dibandingkan dengan menanam di tanah. Sistem hidroponik memiliki banyak kelebihan daripada sistem konvensional dalam bertanam.

Budidaya tanaman hidroponik diharapkan menjadi pemicu bagi pengembangan masyarakat di bidang kesehatan dan ekonomi. Hasil bercocok tanam hidroponik dijamin kesehatannya karena tanpa pestisida, sehingga dapat di pasarkan di supermarket, hotel maupun apartemen. Untuk berbudidaya tanaman hidroponik sebaiknya dilakukan secara berkelompok, mengingat biaya modalnya cukup besar selain itu dengan berkelompok dapat menjadi pengikat antar anggota.datang.

\section{DAFTAR PUSTAKA}

Benton J. Jones, dkk,. 2014. Complete Guide for Growing PlantsHydroponically, South Carolina, USA: CRC Press Taylor \& Francis Group.

Bernstein, Sylvia. 2011. Aquaponic gardening (a step-by-step guide to raising vegetables and fish Together). Canada: New Society Publishers.

https://id.wikipedia.org/wiki/Hidroponik

https://sumansutra.wordpress.com/tanamanhidr/ 